\title{
Road Pricing: A solution to Ghana's Traffic Congestion
}

\section{Charles Andoh}

Department of ...

University of Ghana Business School

\section{Lord Mensah}

Department of ...

University of Ghana Business School

\section{Daniel Quaye}

Department of ...

University of Ghana Business School

\section{Correspondence:}

University of Ghana Business

School

P. O. Box LG ...

Legon - Ghana.

email address:

Imensah@ug.edu.gh https://dx.doi.org/10.4314/ajmr. v27i1.8

\begin{abstract}
Congestion in major cities around the world calls for the proper management of space vehicles occupy on road networks. The paper develops models that combine the density of car usage in an area, space occupies by vehicles and the damage they cause to roads in the payment of vehicle registration, renewal, and towing rates. The paper confirms that larger vehicles cause greater congestion on roads by virtue of the space they occupy and causes greater damage to the road, as compared to small-sized vehicles. Vehicles should pay road rates commensurate with the density of vehicles, the space they occupy and the damage they cause to the road. From our models, Mercedes-Benz and Toyota, Camry are undercharged across all the offices in the country, except for Tema and Bolga, which charges 120 and 80 Ghana cedis respectively above the 60 Ghana cedis national charge. For new car registration fees, we found that the current charge is higher for New Audi A1 Sportback 2019 except at the Tema registration office, which charges more than 20 Ghana cedi above the national charge of 100 Ghana cedis. The paper also provides models for costing the removal of vehicles that park at unauthorized places as well as broken-down vehicles on highways. The paper suggests that this method of road user rates payment, aside being a good source of revenue for governments would encourage people to patronize public transport. This will ease road congestion, road rage as well as other unwanted road behaviors, particularly around and within city centres.
\end{abstract}

Key words and phrases: Car density, congestion, damage, space, vehicle registration fees, vehicle renewal fees

\section{Introduction}

It is common to drive to city centres in Ghana and have trouble in getting a place to park. The situation becomes critical, particularly during Christmas, Easter, and public holidays. Vehicles fill parking spaces 
during such occasions, spilling onto the roads thus narrowing the road space for vehicular movements and manoeuvring. Congestion on road networks in cities in Ghana can be attributed to several sources. Firstly, major roads get blocked by drivers of "tro-tro" buses (a form of minibuses for conveying passengers), in their quest to load and off-load passengers. This forces other vehicles to either stop or slows down. Secondly, pavements meant for pedestrians are used as trading places by hawkers and traders. Consequently, pedestrians are forced to share the road with vehicles, slowing down vehicular movement in the process. Thirdly, broken -down vehicles are sometimes left unattended on busy roads obstructing the free flow of traffic. Fourthly, although other roads may be accessible to the city, the bad nature of some of the roads, compels most drivers to use the main roads to the city centre. Limited road transport infrastructure, excessive number of vehicles and road works, pose as added reasons to the congestion on Ghanaian roads. In addition, vehicle ownership represents growing affluence and social status in Ghana. The number of cars in the country has been growing because of improvement in standard of living. People have become accustomed to the ease of mobility through private ownership of vehicles, while public transportation is often perceived as unreliable, inefficient, or inconvenient. Thus, economic activities in the cities are slowing down because of the large number of vehicles on roads. As such, there is the urgent need to find innovative ways to manage Ghana's road congestion.

Vehicle manufacturers produce vehicles of various designs, shapes, and sizes to meet the needs of their customers. Large vehicles are safer to drive than smaller ones. As a result of their heavy weight, they are solid on the road, which allows them to have firmer grip on the road and thus steadier. On the other hand, small cars occupy smaller space on the road and less likely to cause greater damage to the road compared to big cars. They are generally economical to use because fuel consumption is lower compared to the large-sized vehicles. Large vehicles occupy greater space on the road and contributes greatly to congestion compared to smallsized ones. For salon and other small vehicles, Driver and Vehicle Licensing Authority (DVLA), in Ghana charges vehicle registration and renewal fees mainly based on the cubic capacity (CC), but not their size, weight nor the place where the vehicle spends more time. This model for registration charges would have been appropriate in the past when there was a correlation between vehicle cubic capacity and size: the larger the CC, the larger the vehicle. However, in recent times it has become imperative for the size of the vehicles to be considered in the determination of the fees because modern technology allows car manufacturers to design bigger cars with relatively smaller CC. These bigger cars, despite occupying more space and causing more damage to the road, pay lesser road rates because of their registration and vehicle renewal fees being solely based on their CC. Moreover, DVLA vehicle registration and renewal charges does not incorporate the number of vehicles in the region or the city where the vehicle is registered and operates. To compel people to drive less in congested cities and towns, these must be factored in the vehicle registration and the renewal of fees. In Ghana, the application of charges to vehicles that park at unauthorized places have been ad-hoc. The same goes for broken down vehicles that are left unattended on roads. The paper provides pricing models for these cases as well. 
This paper contributes to the existing literature by developing model that uses damage and the space occupied by vehicles to determine the amount to pay for vehicle registration and renewal fees. To the best of our knowledge, the paper is first of a kind to come up with such a model and it will form the bases for further research in traffic congestions in Ghana. Specifically, the paper argues that large vehicles cause greater congestion by virtue of the space they occupy and consequently should pay fees commensurate with the size they occupy on the road and the damage they cause to the roads. We also develop pricing models for vehicles that are left unattended or packed at unauthorized places. These models incorporate the density of the vehicle, the area in which a vehicle operates or spends more time, vehicles left unattended or parked. This mode of vehicle registration and renewal fees can influence a vehicle owner's decision to drive or patronize public transport. The latter option would reduce the number of vehicles on the road. The models will be used to assess whether vehicle registration and vehicle renewal fees are appropriately assigned by DVLA vis-à-vis the space and the damage these vehicles cause to the road. The models will be a huge relief to the DVLA as it struggles to find appropriate models for fairer fee charges. The models will also be useful to organizations that clamp vehicles that park at unauthorized places. It will guide policy on what charges to impose on vehicles parked at unauthorized places as well as broken-down vehicles left on roads unattended. Environmental pollution and its associated costs will hopefully decline as lesser number of vehicles use the road. This will also deter big cars from entering the city and encourage motorists to patronize public means of transport.
The rest of the study is organized as follows. Section 2 contains the literature where a discussion of the car market in Ghana is provided. The development of the model is contained in section 3 whereas the section 4 discusses the results based on the model developed. Section 5 give the summary, concludes, and provides some recommendations for policymakers. Study limitation is also provided in section 6 .

\section{Literature Review}

This section provides an overview of the car market in Ghana, discusses space pricing incorporating the reasons for space pricing and the general deterrence theory which underpin the study. Ghana is generally a technology taker: majority of the vehicles used on the roads are imported. Almost every vehicle type can be found in Ghana but small vehicles of up to 2000CC abounds on roads. From data obtained from DVLA, nearly $30 \%$ of all vehicles in Ghana falls in this category as at 2018. As can be seen from Figure 1, from 2008, the number of motorbikes has surpassed the usage of small vehicles of capacity up to 2000CC.

There is currently one indigenous Car Manufacturing Company, Kantanka Automobile (see kantankaautomobile. com). Established by Apostle Dr. Ing. Kwadwo Safo in 1994, it was incorporated as a limited liability Company in 2004 to research into car manufacturing. Since going into commercial production in 2017, it is believed to have produced just over 1000 vehicles with the largest purchase by Government of Ghana in 2019 to encourage local patronage. The current vehicles manufactured by Kantanka Automobile and their price list is indicated in the table below. 
Table 1: Vehicle type and Prices

\begin{tabular}{ll}
\hline Kantanka Vehicle Model & Price $(\mathbf{G H} \boldsymbol{\phi})$ \\
\hline Onantefo & 150,000 \\
Omama Luxury & 130,000 \\
Omama Ordinary (4×4), & 95,000 \\
K71 & 65,000 and 70,000 \\
Amoanimaah & 70,000 \\
Mensah & 130,000 \\
\hline
\end{tabular}

The vehicles are designed to meet the challenging needs of the African road networks. However, Kantanka Automobile vehicles have, however, been criticized by the public as over-elaborated and expensive ( $1 \$ \approx \mathrm{GH} \phi 5.66)$, for the average worker in Ghana. Thus, questioning the market target of the vehicles manufactured by Katanka Automobile.

The dynamics of global transportation landscape has made it difficult to restrict the use of vehicles. Consequently, government through regulatory agencies resorts to fiscal regimes to control the purchase, circulation, and movement of vehicles as strategy to reduce the negative impact on the environment (Mabit, 2014). Over time, studies have established that raising taxes as a control measure in the car sector have always received opposition prompting scholars to explore alternative measures (Arnberg, Bjørner, Fosgerau and Larsen 2008). Space pricing has been identified as an effective fiscal measure for controlling the high spate of congestion and its associated environmental impact of emission and congestion. According to Bull (2003), space pricing is an integrated framework of charging vehicles for occupying an authorized or unauthorized space based on weight and space occupied. Similarly, space pricing is seen as an allocation of space to road users and charging them a fee for the space occupied. The practice of space pricing involves allocating traffic space to vehicles based on their size, time of the day and space occupied by the vehicle at a fee. Studies have established that vehicular buyers and users are more sensitive to price (Greene, Evans and Hiestand 2013; Killian and Sims, 2006).

The effect of fiscal policies has been widely recognized in emerging literature even though no consensus exists especially in European countries employing fiscal measures in the Automobile sector (Bergantino, Intini, and Percoco, 2019). According to Bergantino et al. (2019), Superbollo fiscal regime in the automobile sector had a positive effect on the reduction of carbon emission and $\mathrm{kW}$ (engine power of vehicles expressed in Kilowatt). The study further noted that the effect of a fiscal regime is only realized when people buy cars with smaller engines. According to Hennessy and Tol (2011), space pricing is to serve as a measure to control for carbon dioxide emission, shifting the sale and purchase of petrol cars to diesel cars in Ireland. Cavallaro, Giaretta and Nocera (2018), established that it aimed at raising funds to regulate demand for traffic space, manage roads, and to reduce excessive and unauthorized parking and circulation of vehicles. Hibbs's (2004), argument corro- 
borate the work of Cavallaro et al. (2018), that charging vehicle owners for parking space at a particular time of the day is an efficient strategy to road use which reflect in a low level of road congestion, particularly in the cities.

Space pricing continues to grow because population and economic activities in the cities continue be on the surge (Downs, 2004). Obviously, due to limited road parking capacity, space pricing solutions has become necessary to improve road capacity use, mostly in the city where congestion is high (Bull, 2003). Unauthorized parking causes traffic congestion and environmental hazards that are more difficult to quantify in terms of waste and environmental pollution. Recent studies have alluded to the fact that there is a health consequence on people living in vehicular congested areas (Invernizzi, Ruprecht, Mazza, De Marco, Močnik, Sioutas and Westerdahl, 2011). Hence, charging vehicles for authorized use of road will improve the efficiency of road use and reduce congestion (Bull, 2003). Apparently, lack of policy attention from city road regulators and its ramifications have led to scholars calling for an integration of land use and the transport system as a strategy to improve the negative effect of city congestion (Zhao, 2010; Cervero, 2013; Zegras, 2012).

According to Cavallaro et al. (2018), the rationale for space pricing is straightforward in a form of reducing congestion, lost time, pollution and cost of road accidents. It is to reduce congestion, save lost time, pollution and minimise the cost of road accidents. Even though space pricing schemes may not be the only scheme to control unauthorized vehicle parking and traffic congestion, an integrated model that incorporates optimal space pricing scheme as tax policy is important to achieve the objective of space pricing (Button, 1993). The literature identifies many impacts of space pricing model such as weight of the vehicle, peak and non-peak hours and the behaviour of the vehicle user (Sinha and Labi, 2007). The theory further suggests that space pricing might be more efficient (Arnott, De Palma and Lindsey, 1993), but the efficiency of space pricing will depend on the responses of the vehicle users (Gibson and Carnovale, 2015). Indeed, the behavioural dimensions of space pricing, and the behaviour of road users are key to ensure successful achievement of space pricing policy.

Integrating space management strategies into tax structure and policy in developing countries has become a new paradigm for controlling vehicle congestion. Over the years, the idea of taxation has remained an important source of revenue for the Ghana government. Government agencies and institutions are always devising taxation models to widen tax "bracket" and also enhance tax compliance and collection. Superbollo tax was introduced in Italy in 2011 for car exceeding $185 \mathrm{~kW}$ (Berganitino et al., 2019). According to Berganitino et al. (2019), Superbollo fiscal regime in the car sector had a positive effect on the number of cars circulating and also reducing larger capacity cars. Similarly, Gervasoni and Sartori (2007), noted that different road pricing systems such as road tolls, value pricing, high occupancy tolls, travel distance-based charging, travel time-based charging, road space rationing, cordon-based charging, zonal schemes, satellite-based road pricing 
schemes exist.

The transport industry is one of the avenues for the implementation of fiscal regimes including a collection of driver and vehicular license and toll charges among others. Several avenues exist in the transportation industry for the government to control movement, parking and dis-use of environmental unfriendly vehicles. Even though these charges may seem confusing, they all serve different purposes. Mabit (2014), established that in Denmark, for instance, vehicular tax reform has a significant impact on vehicle purchase behaviour. Berganitino et al. (2019), noted that the Superbollo tax resulted in a behavioural change towards greener cars, thus reducing the emission of carbon dioxide.

From a behavioural perspective, awareness and persuasion of vehicle users about the existence of vehicle incentives are important in controlling the use and movement of vehicles in the environment (Cerruti, Daminato and Fillipini, 2019). They showed that vehicle owners who are aware of the incentives will be encouraged to exhibit good behaviour to take up the monetary benefits.

Governments and city authorities have used space pricing as a strategic tool to control antisocial behaviour and generate public revenues (Croci, 2016). These strategies have yielded some significant result in controlling traffic and vehicular congestion on roads, especially in the cities. Despite the strategic nature of space pricing, the problem of unauthorized parking and congestion remain which precipitate the fact that unauthorized parking and congestion requires more than persuasion. Cole (1998), noted that there are some instances which create recurrent high demand at certain times, thus creating road congestion. In view of this, extant literature opined that a high number of vehicles in a country must relate with increase fiscal regimes (Button, 1993). The effectiveness of the relationship between space pricing strategy and taxation has, however, received attention in terms of anti-social welfare (Raux, 2005), and pollution abatement in cities (Eliasson, Hultkrantz, Nerhagen and Rosqvist, 2009). In a survey by Vrtic, Schuessler, Erath and Axhausen (2010), behavioural responses of the vehicle users are also essential in the integration of space pricing and taxation policy.

A study by Dargay, Gately and Sommer (2007), examined the relationship between annual growth in GDP per capita and vehicle growth per 1000 inhabitant in 45 nations, representing 75 per cent of the world's populations. The study found that vehicle fleets of the world in 2002 was around 800 million and was predicted to increase to 2 billion in 2030. They showed that not only has ownership of cars increased but also the usage of vehicles, particularly in the cities. Importantly, findings from this study suggest that increase in vehicle use on roads has the potential to contribute to traffic congestion, hence a pricing scheme for parking space will significantly improve congestion situation and also generate revenue for the government. In a pluralist perspective, vehicle users must be held responsible at different levels to pay a price that fully captures the problem caused (Croci, 2016). According to Bull (2003), the charge for unauthorized parking and parking space must take into consideration a high number of vehicles 
used especially in peak hours where demand for the road usage is high.

Downs (2004), and Bull (2003), opined that the desire to live in low-density settlements and government policies contributed to the increase in car ownership and usage. Similarly, as policy prescription, governments as a policy prescription must integrate the ownership and usage of vehicles into the tax policy where people are taxed based on the space and weight occupied by the vehicle. In such a practice, public-private collaboration can be enhanced which will ensure that specialized places are designed for vehicles to park for a fee. Consequently, this integration will reduce time lost due to congestion, local pollution, noise, pavement costs and road damages, increase in accidents risks (Croci, 2016).

Extant literature confirmed several determinant of space pricing policy such as space occupied, time, size of vehicle and number of travels, as a strategy to generate revenue and control traffic behaviour (Tiwari, Cervero, and Schipper, 2011; Ewing and Cervero, 2010; Givoni, Brand and Watkiss, 2009). Integration of space pricing base of space, weight and time of the day means that people will drive only when the benefits from driving outweigh the sum of the costs, which include prices to be paid (Newbery, 1988; 1990). Phang and Toh (2004), further noted that space pricing policy captures tolls per entry where vehicle are charge based on size, route taken, and time of the day. In Milan for instance, a congestion charge is implemented concurrently with the space occupied, time and park-andride facilities (Rotaris, Danielis, Marcucci and Massiani, 2010). These strategies generate revenue for the government while controlling road congestion and unauthorized parking on roads. Peculiar to Ghana, integration of space pricing into the tax policies means that government must enhance the operations of public Bus Rapid Transport, Metro Transport and State Transport which will convey commuters.

This research, therefore, proposes an integration of a model which incorporates space pricing approach into fiscal regimes such as space pricing policy. In such as integration, space price or toll should consider four key elements including the size of the vehicle, weight, space occupied and routes taken by the vehicle. An integrated approach will mean the ability to charge these vehicles for parking either in government or private designated parking space. Consequently, this initiative will reduce externalities such as authorized parking, road congestion, accidents, while generating money for the state.

The General Deterrence Theory (GDT) is adopted to underpin this study. According to Cuccia (1994), behavioural compliance is primarily viewed from General Deterrence Theory, which posits that individuals can be dissuaded from engaging in antisocial acts by using countermeasures including disincentive and sanctions (Schuessler, 2009). General Deterrence Theory is adopted for this study to understand how states can use countermeasures such as taxes to positively influence the wrong parking behaviour of vehicle users. Schuessler (2009), noted that using GDT as a guideline, countermeasures such as education, training and reprimands are important to mitigate, eliminate and/or prevent the occurrence and reoccurrence 
of behaviour. This study expands the tenants of this conceptual view of GDT to include non-human measures such as taxes as an approach to deter vehicle users from unauthorised parking and also generate revenue for the government. In order for the integration between space pricing and tax to yield result, vehicular users' needs to show positive behaviour towards traffic space.

\section{Methodology and Model Development}

Following the taxonomy of Phang and Toh (2004), space price or toll must inculcate four key dimensions which will deter people from unauthorized behaviour and at the same time generate revenue from those who will opt to park. This paper proposes that space price factors such as vehicle weight, size of the vehicle, vehicle concentration in an area and the length of time a vehicle is abandoned on the road should be used as indicators to determine prices thus ensuring fairness as well as creating revenue for government. Again, the behaviour of the road users (whether they heed to the proposed changes or otherwise), will determine the degree of deterrence, and the revenue that the government would generate. The models have been developed for these categories of vehicles: conforming vehicles, vehicle registration, break down vehicles, left on roads (classified as risky), and vehicles packed at unauthorized places.

To compute the taxes for well-behaved vehicle owners, let $T_{i j t}$ be the tax paid by vehicle $i$ in region $j$ within a given period $t$ and suppose that the surface area of vehicle $i$ is $S_{i}$. Let $D_{i t}$ be the damage to road caused by vehicle $i$ within a given period $t$. The greater the damage caused by a vehicle to the road, the greater the amount of funds needed to put the road in good shape. Therefore, we set $T_{i j t}$ to be directly proportional to $D_{i t}$. Moreover, the greater the surface area of the vehicle, the lesser the space available for other road users i.e. creating more inconvenience on the road therefore paying more tax (sin tax). Consequently, we set $T_{i j t}$ to be directly proportional to $S_{i}$. We can thus write

$$
T_{i j t}=K_{j} S_{i} D_{i t}
$$

where $K_{j}$ is the constant for the town or city $j$, the town or city of registration of the vehicle $i$. We call $K_{j}$ the car density (compare with Freund and Bertsimas (2004), pp. 283-284 where they computed sales per population that they called sales density). The town or city constant is estimated as

$$
e^{\frac{N_{j}}{P_{j}}}
$$

where $N_{j}$ is the number of vehicles in the town or city $j$ and $P_{j}$ the population in town or city $j$.

Remark 1: $K_{j}$ penalizes the vehicle owner in regions where greater number of people possesses their own vehicle. The constant $e$ can be adjusted depending on the severity of the congestion. In the general case, $K_{j}$ is estimated by

$$
a^{\frac{N_{j}}{P_{j}}}
$$

where $a \in \mathfrak{R}^{+}, a \neq 1$.

$K_{j}$ increases as $a \rightarrow \infty$ and decreases as $a$ $\rightarrow 0$. If $a=1$, then congestion does not matter in payment of taxes which we rule out. 
The heavier the vehicle, the greater the likelihood that a vehicle will cause damage to the road. In addition, the greater the mileage covered within a given period $t$, the greater the chance that a vehicle will cause damage to the road. Therefore, we estimate $D_{i t}$ by multiplying the weight of the vehicle $W_{i}$ and the mileage covered within period $t, M_{t}$. That is

$$
D_{i t}=W_{t} M_{t}
$$

Compare with Andoh and Quaye (2017), pps. 423 and 432.

Consequently,

$$
T_{i j t}=K_{j} S_{i} W_{i} M_{t}
$$

Proposition 1: If $P_{j} \gg N_{j}$ then

$$
T_{i j t} \approx\left(1+\frac{N_{j}}{P_{j}}\right) S_{i} D_{i t}
$$

To see this, observe that

$$
\begin{array}{r}
K_{j}=1+\frac{N_{j}}{P_{j}}+\left(\frac{N_{j}}{P_{j}}\right)^{2}+\left(\frac{N_{j}}{P_{j}}\right)^{3}+ \\
\ldots \approx 1+\frac{N_{j}}{P_{j}} \quad \text { for } P_{j}>>N_{j} .
\end{array}
$$

This proposition says that in regions or cities where the number of vehicular usage is far less than the population, then the car density can be approximated by

$$
1+\frac{N_{j}}{P_{j}}
$$

Proposition 2: If $P_{j} \approx N_{j}$, then $T_{i j t} \approx e S_{i} D_{i t}$.

This proposition provides the tax that must be paid by a vehicle owner in regions or cities where almost every person has a vehicle.

Proposition 3: $T_{i j t} \in\left[S_{i} D_{i t}, e S_{i} D_{i t}\right]$ for $N_{j} \in$ $\left[0, P_{j}\right]$.

This proposition says that the maximum a vehicle owner must pay as tax should not exceed $e S_{i} D_{i t}$ and no one should pay an amount lower than $S_{i} D_{i t}$ as a road user provided the number of vehicles do not exceed the population. The proposition provides guidelines to vehicle owners on the amount they have to pay as tax for usage of vehicles.

Proposition 4: If $N_{j}>P_{j}$, then

$$
T_{i j t} \approx e S_{i} D_{i t} e^{\frac{C_{j}}{P_{j}}} \quad C_{j} \in \mathrm{Z}^{+}
$$

To see this, observe that if $N_{j}>P_{j}$, we can write $N_{j}>P_{j}+C_{j}$ for $C_{j} \in \mathrm{Z}^{+}$. Then

$$
K_{j}=e^{1+\frac{C_{j}}{P_{j}}}=e e^{\frac{C_{j}}{P_{j}}}
$$

The result then follows from equation (2).

$C_{j}$ can be interpreted as the additional units of cars beyond the population. This proposition indicates that if the number of cars exceed the population in a particular region, vehicle owners must pay taxes which depends on exponentially growth of the additional unit of cars beyond the population. That is, the vehicle user pays more taxes if the vehicle is been used in a region where the number of cars exceeds the population.

Propositions 3 and 4 can be used to verify whether the taxes imposed on luxury vehicles introduced in August 2018 by the Ghana government are fair. 
In order to compute vehicle registration fee (which is a requirement by law of all vehicles imported or manufactured in Ghana), let $T_{i j}$ be the fees paid by vehicle $i$ in region $j$ and set

$$
T_{i j}=\delta K_{j} S_{i} W_{i}=\delta e^{\frac{N_{j}}{P_{j}}} S_{i} W_{i}
$$

Equation (3), take into account the car density which penalizes the user for registering in regions where the volume of vehicles is high. $\delta$ is the mileage constant, a proxy for the age of the vehicle and penalizes the user for vehicles with greater mileage. The higher the mileage covered by the vehicle, the greater the likelihood that the vehicle will either break down and obstruct other road users. In addition, such vehicles pollute the environment the most and users of such vehicles must pay for the mess. Thus $\delta$ is to deter people for importing overused or over age vehicles into the country. The surface area of the vehicle $S_{i}$ and the weight of the $W_{i}$ of the vehicle also has a direct feed into the vehicle registration fee.

To compute the taxes required for vehicles that breakdown on roads, let $L_{t}$ be the length of time a vehicle is abandoned on a highway and $p$ the position where the vehicle is abandoned. Let $\check{T}_{i j t}$ be the $\operatorname{tax} /$ fee paid by vehicle $i$ in region/city $j$ for an abandoned vehicle for a period $t$.

We set $\check{T}_{i j t}$ to be partly fixed and varies directly as $L_{t}, S_{i}$, and $D_{i t}$ and so we can write

$$
\check{T}_{i j t}=m_{p}+K_{j} S_{i} D_{i t} L_{t}
$$

where $m_{p}$ and $K_{j}$ are constants. Call $m_{p}$, the position constant, the place where the vehicle is abandoned. The position where the vehicle is abandoned will be described as risky or risky-free. We estimate $m_{p}$ by the going market rate for towing abandoned vehicle. If a vehicle is abandoned at a risky place, then the going market rate of towing that abandoned vehicle apply otherwise $m_{p}$ is zero.

Remark 2: It should be noted that in computing $K_{j}$ in (4), the region $j$ where the vehicle is abandoned is used.

Risky positions are places where vehicles are abandoned in curves, at junctions, in hilly areas, zebra crossings, railway crossings and places where the vehicle seriously obstruct free flow of traffic.

Remark 3: For vehicles abandoned at risk-free positions, we place a maximum allowable time of two days beyond which equation (4), will apply to the vehicle owner.

Proposition 5: If $P_{j}>>N_{j}$ then

$$
\check{T}_{i j t}=m_{p}+\left(1+\frac{N_{j}}{P_{j}}\right) S_{i} D_{i t} L_{t}
$$

Proposition 6: If, $P_{j} \approx N_{j}$ then

$$
\check{T}_{i j t}=m_{p}+e S_{i} D_{i t} L_{t}
$$

Proposition 7: For all abandoned vehicles, the amount charged lies in

$$
\left[m_{p}+\left(1+\frac{N_{j}}{P_{j}}\right) S_{i} D_{i t}, m_{p}+e S_{i} D_{i t} L_{t}\right]
$$

provided $N_{j} \in\left[0, P_{j}\right]$

This proposition gives the vehicle owner a sense of how much must be paid for vehicles that are abandoned on highways. 
Proposition 8: If $N_{j}>P_{j}$ then

$$
\check{T}_{i j t}=m_{p}+e S_{i} D_{i t} L_{t} e^{\frac{C_{j}}{P_{j}}}
$$

where $C_{j}$ is as defined in proposition 4 .

This proposition means that if a vehicle is abandoned in a region where the number of cars exceed the population, vehicle owners must pay taxes which depends on exponentially growth of the additional unit of cars beyond the population, the surface area, the damage it causes plus the cost of towing the vehicle.

To compute taxes for vehicles parked at unauthorized places, we let $\check{T}_{i j t}$ ( to be partly fixed and varies directly as $S_{i}$ and $L_{t}$ and so we can write

$$
\check{T}_{i j t}=m_{p}+K_{j} S_{i} L_{t}
$$

if there the need to tow the vehicle and

$$
\check{T}_{i j t}=K_{j} S_{i} L_{t}
$$

if there is no need to tow the vehicle parked.

\section{Model Test, Results and Discussions}

This section tests the models developed on vehicles that typically ply on the Ghanaian roads.

Data for the analysis was obtained from Driver and Vehicle Licensing Authority (DVLA), and Ghana Statistical Service. From DVLA, we obtained data on the number of registered vehicles that operates on the Ghanaian road space from 1995 to 2018, the number of vehicle registration offices, vehicle roadworthy charges and vehicle registration charges. The population data for regions/cities where DVLA operates were obtained from the Ghana Statistical Service website.

Figure 1 below shows the plots of the number of selected vehicles registered from 1995 to 2018.

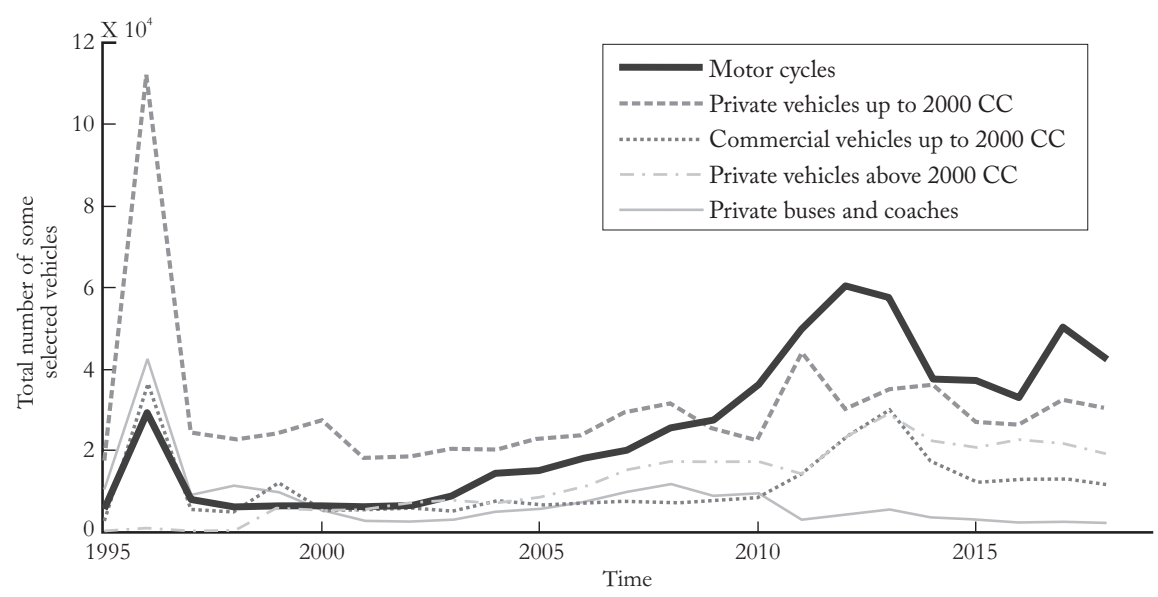

Figure 1: Total number of some selected vehicles from 1995 to 2018. 
Overall, there is gradual increase in the number of vehicles on the road from 1997 to 2018 . In 1996, there was re-registration of all vehicles and that can be seen in the upsurge of all vehicular types during this period. DVLA normally does this to check for fraudulent registration. From 2008, the use of motorcycles has become popular among Ghanaians surpassing the use of private vehicles up to 2000 CC. From Figure 1, the use of private coaches is on a slight decline. On the other hand, private vehicles with engine capacity above $2000 \mathrm{CC}$ is on the ascendancy. This can be attributed to the bad nature of some roads in many parts of the country which require these vehicles to access with minimal breakdown of one's vehicle.
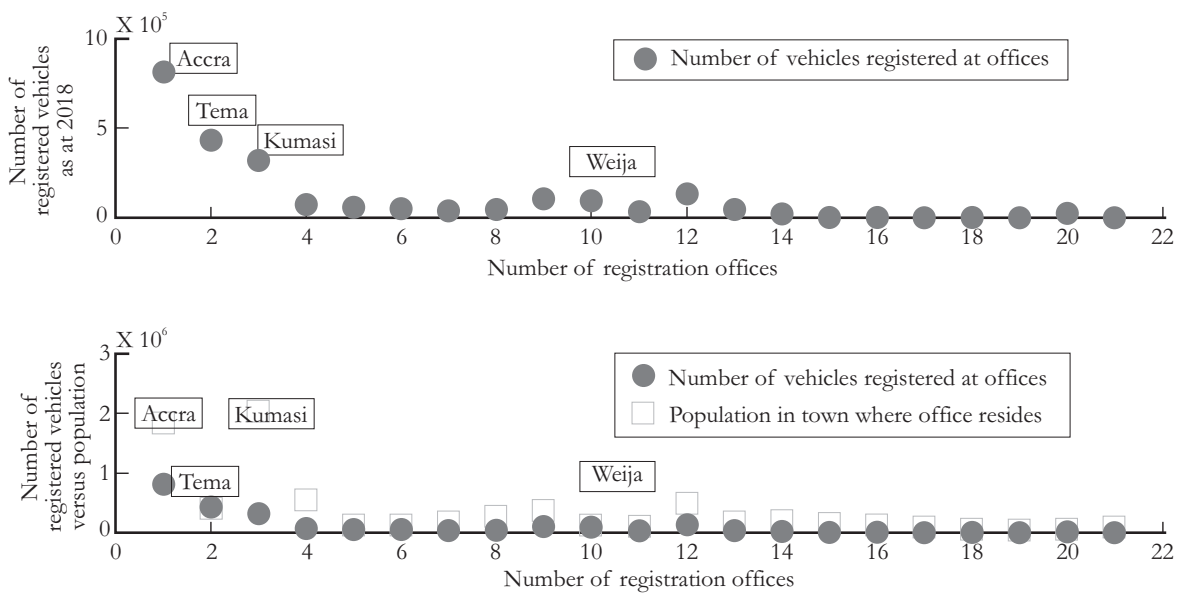

Figure 2: Upper plot: Number of registered vehicles across Ghana as at December 2018 Lower plot: Number of registered vehicles and the population in the city where office resides

The number of registered vehicles for the various offices at the end of December 2018 lies in [701, 816473], with Accra recording the greatest number of registered vehicles. This can be seen from the upper plot of Figure 2. Other offices with high number of registered vehicles are Tema, Kumasi and Weija. The office with the least number of registered vehicles is Danu, in the Volta region of Ghana. The lower plot compares the number of registered offices with the population of the town where the office resides. It can be seen from the lower plot of the Figure 2 that although Kumasi is the third in terms of number of vehicles, it has the largest population. Table 6 in the appendix shows numerical numbers that have been used to designate the registration offices. For example, '1' stands for Accra, '2' for Tema, '3' for Kumasi, and so on. 


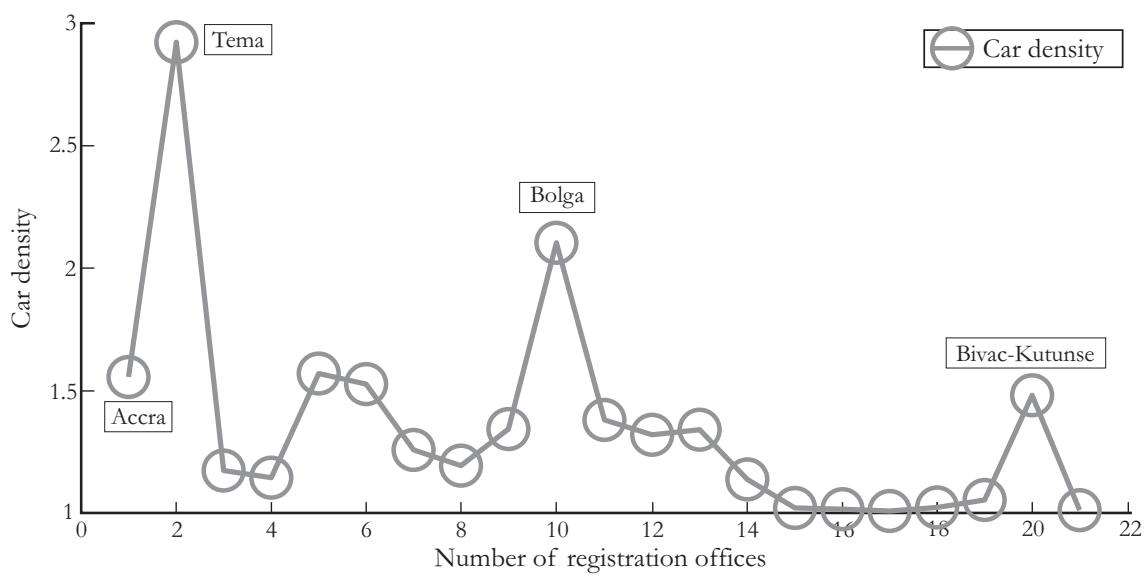

Figure 3: The car densities for the 21 registration offices.

The car density, $K_{j}=e^{\frac{N_{j}}{P_{j}}}, j=1, \ldots, 21$, is depicted in Figure 3. Tema has the greatest concentration of vehicles and consequently has the greatest car density. Thus, people residing in Tema will pay the most for purchasing vehicle for their daily routines. The car density of vehicle registered in Tema is approximately two times that of a vehicle registered in Accra. This is followed by Bolga, Accra and BivacKutunse.

We illustrate how much fees have to be paid using three different brands of vehicles: Mercedes-Benz C-Class, New Audi A1 Sportback 2019 and Toyota Camry 2018. From equation (2),

$$
T_{i j t}=K_{j} S_{i} W_{i} M_{t}
$$

Because DVLA does not keep records of mileage that comes for renewal of roadworthy certificates and vehicle registration, we assume that these three vehicles cover a mileage of $50000 \mathrm{~km}$ within a given period $t$. The dimensions (surface area), of the vehicles are computed in kilometres to be consistent with the mileage. Also, the weights are computed in tons. The results obtained can be seen in Table 2 (see Appendix).

Note: The units of $T_{i j t}$ is tonsk $\mathrm{m}^{3}$ and we have chosen 1 tonsk $\mathrm{m}^{3}$ to be equivalent 1 GHc in Table 2 above. It should also be noted that $1000 \mathrm{~kg}$ is equivalent to 1 ton.

It can be seen from Table 2 the discrimination in the prices for the different registration offices. For example, the owner of Mercedes-Benz C-Class registered in Tema pays GHc 185.04 as fees and the same vehicle registered at Mampong pays GH $\varnothing 3.81$, about one-third of the fees charged at Tema. Also, observe the differences in the fees for the three categories of vehicles. Toyota Camry 2019 is the most expensive to use among the three vehicles for all registration offices largely because of the area it occupies on the road. 


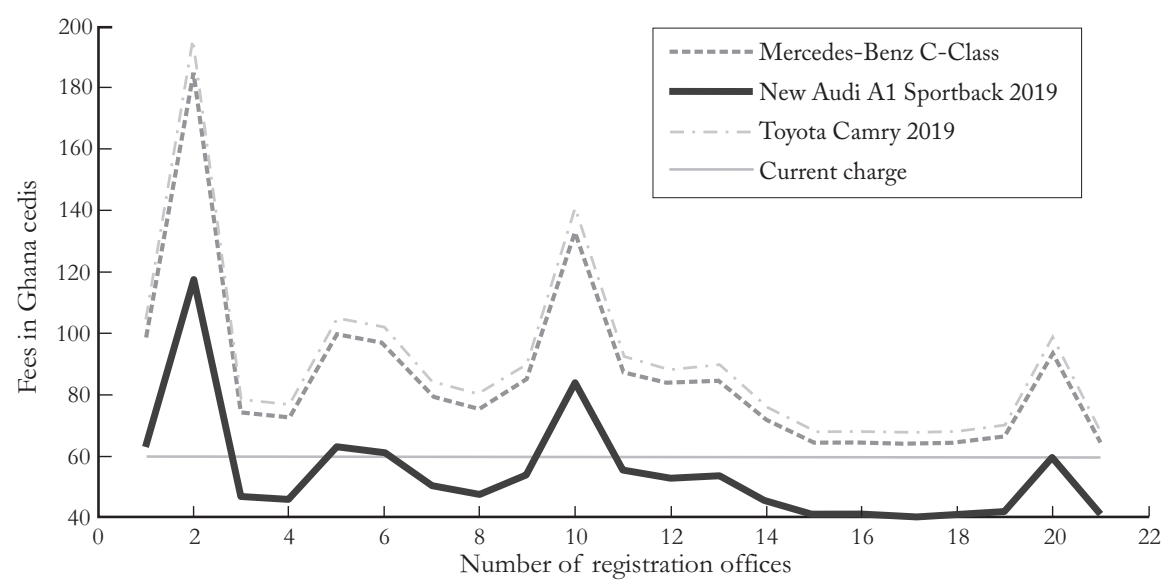

Figure 4: Fees for registration offices for different vehicles with current charge.

Figure 4 shows the fees for these vehicles with the current charge super-imposed. Clearly, Mercerdes-Benz C-Class and Toyota Camry 2019 are undercharged for all registration offices.

For registration of vehicles to be used on the road for the first time, we use equation (3), to determine the fees shown in table 3 (see Appendix) for a year old of all three vehicles. In computing the values shown, $\delta$ is measured in weeks and the dimensions of $S_{i}$ are in kilometres.

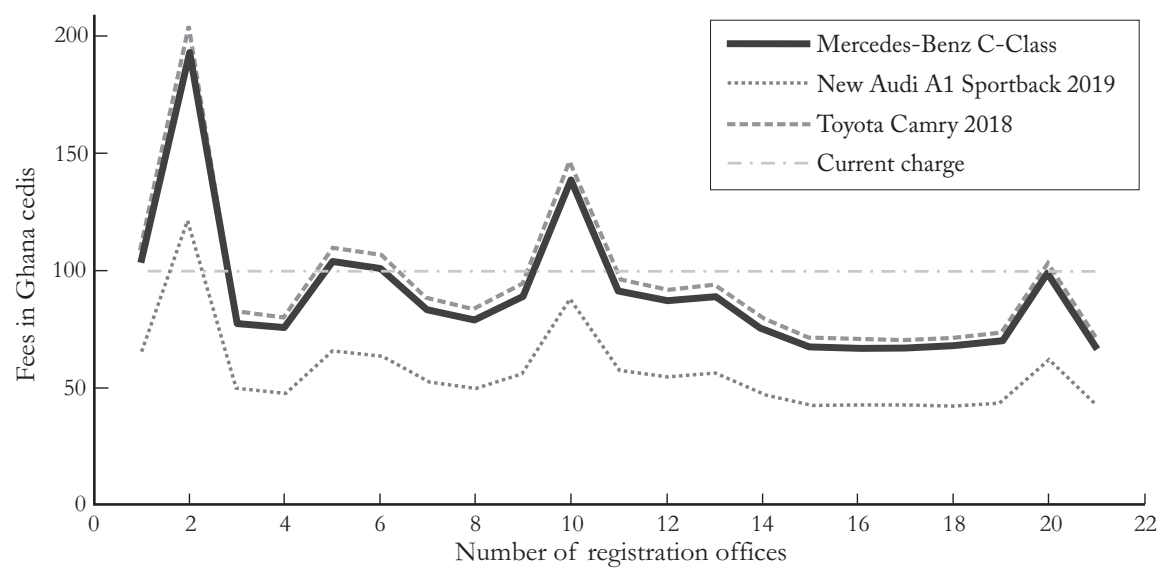

Figure 5: Fees for a year old three categories of vehicles at different registration offices with current charge imposed.

From Figure 5, the current charge is higher for New Audi A1 Sportback 2019 except at Tema registration office. The fees, however, rises relatively fast with the 
age of the vehicle especially for cities with high car densities.
Checking the fairness of the Luxury taxes

Table 5 shows the engine capacities of vehicles and the corresponding levies the government of Ghana imposed on August 1, 2018.

Table 5: Government levies of Luxury vehicles

\begin{tabular}{lll}
\hline Number & Engine Capacity (CC) & Levy $(\mathbf{G H} \boldsymbol{\phi})$ \\
\hline 1. & $2950-3549$ & 1000 \\
2. & $3550-4049$ & 1500 \\
3. & Above 4049 & 2000 \\
\hline
\end{tabular}

We use our models to determine how much should be paid for three categories of vehicles, one of each category of Table 5. These vehicles are Jaguar F-TYPE Coupe with engine capacity 3000CC, Chevrolet Colorado ZR2 with engine capacity 3600CC and 2019 Jeep Cherokee Sport with engine capacity 5900CC. We assume that these three vehicles cover a mileage of $50000 \mathrm{~km}$ within a given period $t$. The fees for each category of vehicle is as depicted in Figure 7. Even if the mileage is doubled, the fee at the greatest car density does not reach the least value indicated in Table 5.

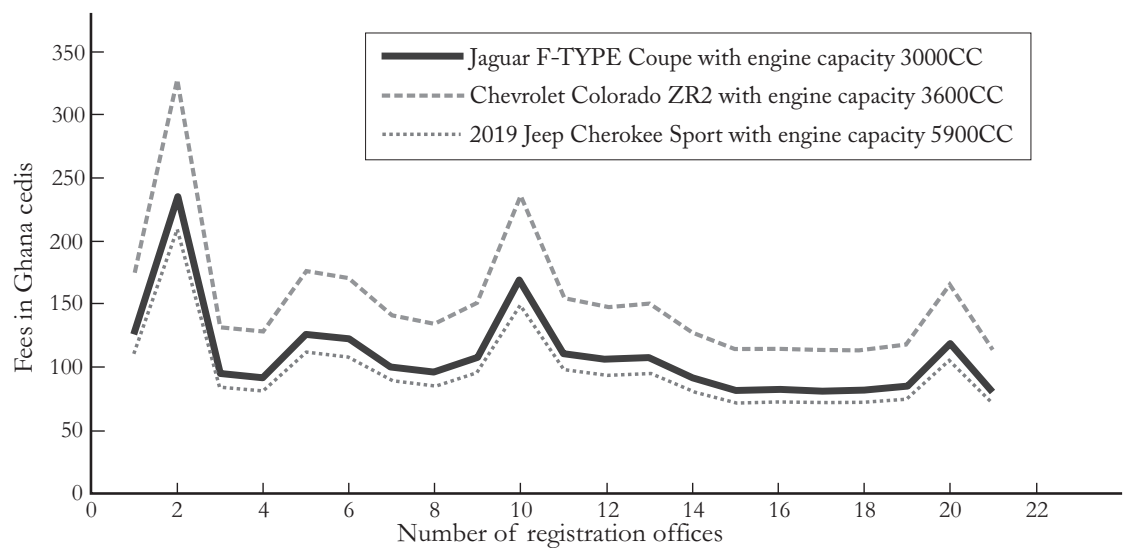

Figure 6: Fees for luxury vehicles with engine capacity 3000CC, 3600CC and $5900 \mathrm{CC}$ at different registration offices.

As can be seen from Figure 6, these fees are well below the levies that the government imposed even for cities with high car densities.

Suppose that $m_{p}=200$ and that $L_{t}=2$ hours or 120 minutes, Table 4 (see
Appendix) shows the charges for the three categories of vehicles for the different cities where a breakdown of vehicle occur. For example, in computing the charges for Mercedes-Benz C-Class, using equation (4), we have 
$\check{T}_{i j t}=200+120 \times K_{j} \times 4648 \times 1810 \times$

$$
1505 \times 10^{-10}, j=1, \ldots, 21
$$

where we have adopted the convention that $1 \mathrm{~km}^{2} \mathrm{~kg} \min =1 \mathrm{GH} \phi$
It should be noted that in computing $\check{T}_{i j t}$, the dimensions of $S_{i}$ were kept in kilometres and the length of time vehicle is abandoned in minutes. Consequently, the units of the second term of $\breve{T}_{i j t}$ is $\mathrm{km}^{2} \mathrm{~kg}$ min.

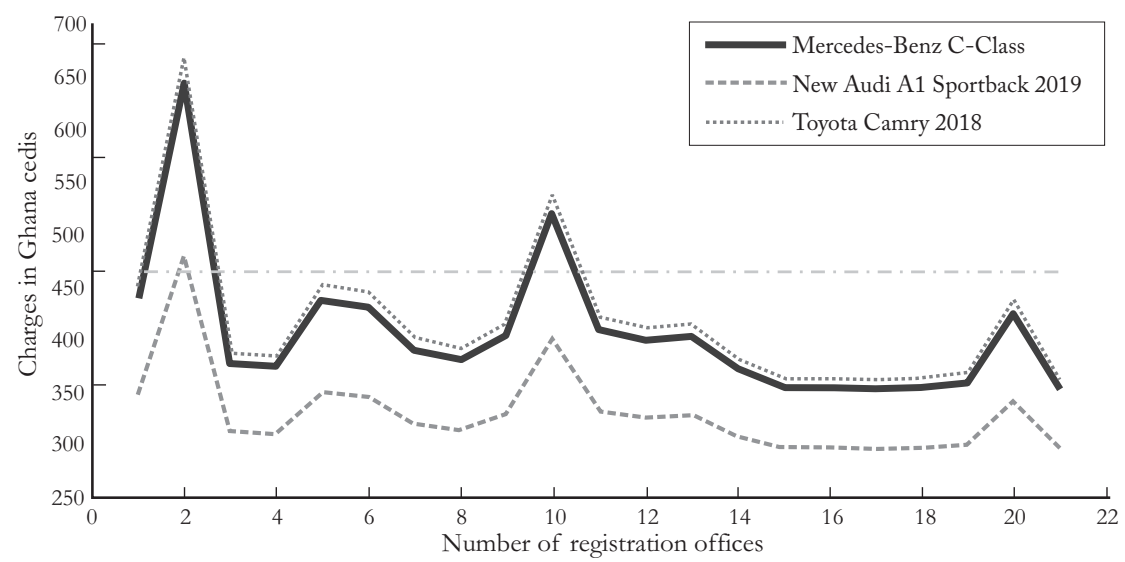

Figure 7: Charges for abandoned vehicles for three categories of vehicles

It can be seen from Figure 7, that fit any country.

abondoning vehicles in the Tema area is most expensive.

Note: In computing these values, the units of measurements can be altered to
Next, we use equation (3) to determine the registration fees for a year old of these vehicles.

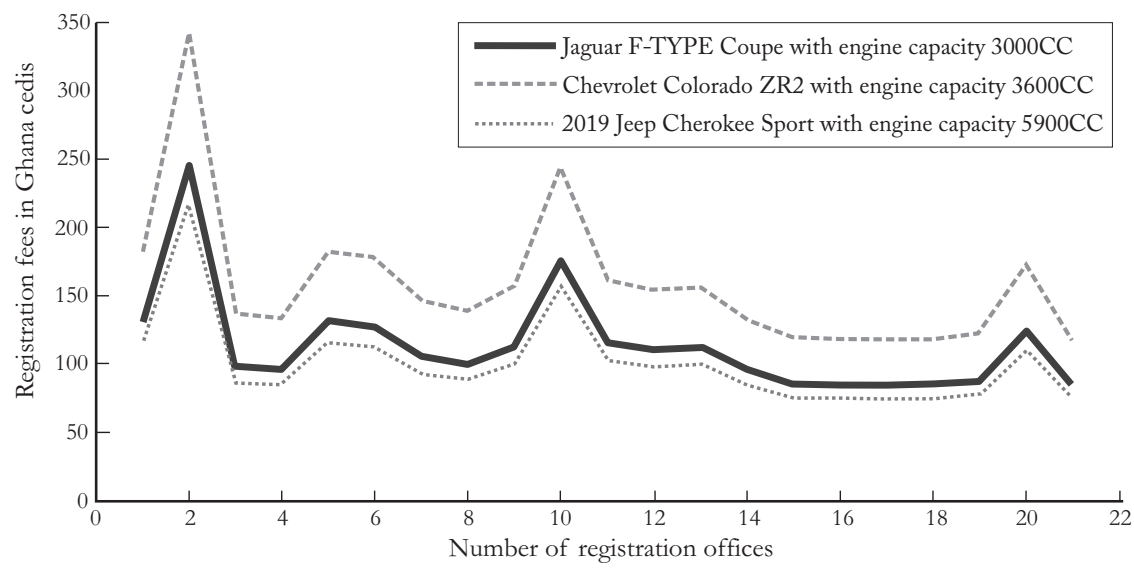

Figure 8: Fees for a year old of three categories of luxury vehicles at different registration offices 
Again, we see from Figure 8 that the fees are lower than the levies charges by the government even for vehicles within 2950CC-3549CC for all registration offices. It should, however, be noted that these fees rise relatively faster with the age of the vehicle especially for cities with high car densities.

\section{Summary, Conclusion and Recommendations}

In this paper we developed models that incorporate the density of car usage in a locality, size and damage caused by vehicles in vehicle registration and renewal fees. The paper also provides models for the cost of removal of vehicles that park at unauthorized places and broken-down vehicles on highways. Specifically, we found that Mercedes-Benz C-class and Toyota Camry 2019 is undercharged across all vehicle registrations centres across the country, except the Tema and Bolga centres which charge 60 and 20 Ghana cedis above the national charge of 60 Ghana cedis. For a year-old cars, we found that the current charge for New Audi A1 sportback 2019 is high, except for the Tema centre which charges 20 Ghana cedis above the national average. Our model also shows that charges for abandoning vehicles on the road are more expensive in the Tema area. This confirms the increase in the charges for car usage in high vehicle concentrated areas.

Our model provides a good decision tool that can be modified to fit any jurisdiction. It allows the decision maker to incorporate the regions of high vehicle concentration in setting vehicle renewal and registration fees. Our models show that some vehicles pay far less for vehicle registration and renewal of roadworthy fees. This strategy of price setting can be used to compel people to move from highly populated areas with high concentration of vehicles to regions of sparsely populated areas to encourage the decongestion of roads nation-wide. Businesses can also be motivated for setting up branches in sparsely populated areas with less concentration of vehicles to benefit from low vehicle registration and renewal fees. This in the long run allow free movement of people, goods and services and serve as source of revenue generation to the Ghana government especially in cities with high vehicle concentration. Also, because there is a direct link between the fees people pay and the mileage covered by the vehicle, some people will be motivated to use their vehicles wisely and will further assist in decongesting roads. In addition, vehicle owners will be conscious on the length of time they have to leave their vehicles on the road anytime there is a break down and will go a long way to free the roads from unnecessary traffic build up. It will help minimize accidents on our roads especially when a vehicle breaks down in a curve.

Consequently, there should be a regulation that compels vehicle owners who register their vehicles in regions of greater usage, to operate them in those regions. Failure to comply should result in heavy fines. Also, DVLA currently do not keep records of the mileage of vehicles that come for registration and renewal of roadworthy certificates at each renewal date. These records have to be kept to facilitate the computation of fees to be paid at each renewal date. We call for the abolitions of toll charges on all government managed roads as they unnecessary slow down vehicular movement. Moreover, it is un- 
clear whether funds collected at these toll gates are properly accounted for by toll gate collectors. Once a vehicle pays its yearly (semi-annually, or quarterly rate at DVLA office), that should suffice.

There is the need for government to take the issue of towing of vehicles seriously at least in major cities and towns. However, this service is currently either not properly organized or unavailable especially for

\section{REFERENCES}

Andoh, C. \& Quaye, D. (2017). Toll Rates and Highway Construction in Ghana: The Concessionary Projects. In K. A. Osei, J. Y. Abor, R. E. Hinson, R. Boateng, J. M. Onumah, K. Dartey-Baah \& A. Ahenkan (Eds.), Contemporary Issues in Management Development in Africa (pp. 415-454). Adonis and Abbey Publishing Ltd.

Arnberg, S., Bjørner, T., Fosgerau, M. \& Larsen, M. (2008). Fuel Costs and Consumers' Choice of Car. AKF, Denmark.

Arnott, R., De Palma, A. \& Lindsey, R. (1993). A structural model of peak-period congestion: A traffic bottleneck with elastic demand. The American Economic Review, 161179.

Bergantino, A., Intini, M. \& Percoco, M. (2019). New car taxation and its unintended environmental consequences. Green Working Paper N5.

Bull, A. (2003). Traffic Congestion. The problem and how to deal with it. ECLAC, United Nations Publications.

Button, K. (1993). Transportation, the Environment and Economic Policy. Edward Algar Publishing Ltd., Aldershot, Hants, 142, 126-144.

Cavallaro, F., Giaretta, F., \& Nocera, S. (2018). The potential of road pricing schemes to reduce carbon emissions. Transport Policy, 67, 85-92.

Cerruti, D., Daminato, C. \& Filippini, M. heavy vehicles.

\section{Study Limitation}

The study uses figures from the last census conducted by the Ghana Statistical Service which is almost a decade old. This will have effect on the estimated car densities and the consequently the prices vehicle must pay for the regions where the vehicles reside.

(2019). The impact of policy awareness: Evidence from vehicle choices response to fiscal incentives. Economics Working Paper Series, 19, 316.

Cervero, R. (2013). Linking urban transport and land use in developing countries. Journal of Transport and Land Use, 6(1), 7-24.

Cole, R. A. (1998). The importance of relationships to the availability of credit. Journal of Banking and Finance, 22(6-8), 959977.

Croci, E. (2016). Urban road pricing: a comparative study on the experiences of London, Stockholm and Milan. Transportation Research Procedia, 14, 253-262.

Cuccia, A. D. (1994). The effects of increased sanctions on paid tax preparers: Integrating economic and psychological factors. The Journal of the American Taxation Association, 16(1), 41.

Dargay, J., Gately, D. \& Sommer, M. (2007). Vehicle ownership and income growth worldwide: 1960-2030. The Energy Journal, 28(4), 143-170.

Downs, A. (2004). Traffic: Why It's Getting Worse, What Government Can Do. No. Policy Brief\# 128), Brookings Institution. Washington.

Eliasson, J., Hultkrantz, L., Nerhagen, L. \& Rosquist, L. S. (2009). The Stockholm congestion-charging trial 2006: Overview of effects. Transportation Research Part A: 
Policy and Practice, 43(3), 240-250.

Ewing, R. \& Cervero, R. (2010). Travel and the built environment: a meta-analysis. Journal of the American Planning Association, 76(3), 265-294.

Freund, R. \& Bertsimas, D. (2004). Data, Models, and Decisions: The Fundamentals of Management Science. Dynamic Ideas.

Gervasoni, A. \& Sartori, M. (2007). Il road pricing: esperienze internazionali, costi, benefici e sostenibilità finanziaria. Liuc Papers, 198. Serie Impresa e mercati finanziari, (6).

Gibson, M. \& Carnovale, M. (2015). The effects of road pricing on driver behavior and air pollution. Journal of Urban Economics, 89, 62-73.

Givoni, M., Brand, C. \& Watkiss, P. (2009). Are railways climate friendly? Built Environment, 35(1), 70-86.

Greene, D. L., Evans, D. H. \& Hiestand, J. (2013). Survey evidence on the willingness of US consumers to pay for automotive fuel economy. Energy Policy, 61, 1539-1550.

Hennessy, H. \& Tol, R. S. (2011). The impact of tax reform on new car purchases in Ireland. Energy Policy, 39(11), 7059-7067.

Hibbs, J. (2004). Transport Economics and Policy: A Practical Analysis of Performance, Efficiency and Marketing Objectives. Kogan Page Publishers.

Invernizzi, G., Ruprecht, A., Mazza, R., De Marco, C., Močnik, G., Sioutas, C. \& Westerdahl, D. (2011). Measurement of black carbon concentration as an indicator of air quality benefits of traffic restriction policies within the ecopass zone in Milan, Italy. Atmospheric Environment, 45(21), 35223527.

Mabit, S.L. (2014). Vehicle type choice under the influence of a tax reform and rising fuel prices. Transportation Research Part A, (64) 3242.

Newbery, D. M. (1990). Pricing and Congestion: Economic Principles relevant to pricing roads. Oxford Review of Economic Policy, 6(2), 22-38.

Newbery, D. M. (1988). Road Damage Externalities and Road User Charges. Econometrica, 56(2), 295-316.

Phang, S. Y. \& Toh, R. S. (2004). Road congestion pricing in Singapore: 1975 to 2003. Transportation Journal, 16-25.

Raux, C. (2005). Comments on" The London congestion charge: a tentative economic appraisal"(Prud'homme and Bocajero, 2005). Transport Policy, 12(4), 368-371.

Rotaris, L., Danielis, R., Marcucci, E. \& Massiani, J. (2010). The urban road pricing scheme to curb pollution in Milan, Italy: Description, impacts and preliminary cost-benefit analysis assessment. Transportation Research Part A: Policy and Practice, 44(5), 359-375.

Schuessler, J. H. (2009). General deterrence theory: Assessing information systems security effectiveness in large versus small businesses. University of North Texas.

Sinha, K.C. \& Labi, S. (2007). Transportation Decision Making - Principles of Project Evaluation and Programming. John Wiley and Sons, New York.

Tiwari, R., Cervero, R. \& Schipper, L. (2011). Driving CO2 reduction by integrating transport and urban design strategies. Cities, 28(5). 394-405.

Vrtic, M., Schuessler, N., Erath, A. \& Axhausen, K. W. (2010). The impacts of road pricing on route and mode choice behaviour. Journal of Choice Modelling, 3(1), 109-126.

Zegras, C. P. (2012). Dynamics of automobile ownership under rapid growth: Transportation Research Record. Journal of the Transportation Research Board, 2323(1), 80-89.

Zhao, P. (2010). Sustainable urban expansion and transportation in a growing megacity: Consequences of urban sprawl for mobility on the urban fringe of Beijing. Habitat International, 34(2), 236-243. 


\section{APPENDIXES}

Table 2: Renewal fees for three categories of vehicles at different registration offices

\begin{tabular}{|c|c|c|c|}
\hline Registration office & Type of Vehicle & & \\
\hline & $\begin{array}{l}\text { Mercedes-Benz } \\
\text { C-Class } \\
50000 \text { mileage } \\
\text { (Fees in GH } \phi \text { ) }\end{array}$ & $\begin{array}{l}\text { New Audi A1 } \\
\text { Sportback } 2019 \\
50000 \text { mileage } \\
(\text { Fees in GH } \phi)\end{array}$ & $\begin{array}{l}\text { Toyota Camry } 2018 \\
50000 \text { mileage } \\
\text { (Fees in GH } \phi \text { ) }\end{array}$ \\
\hline Accra & 98.46 & 62.15 & 104.11 \\
\hline Tema & 185.04 & 116.80 & 195.66 \\
\hline Kumasi & 74.13 & 46.79 & 78.39 \\
\hline Takoradi & 72.45 & 45.73 & 76.61 \\
\hline Sunyani & 99.24 & 62.64 & 104.93 \\
\hline Koforidua & 96.43 & 60.87 & 101.96 \\
\hline Cape Coast & 79.52 & 50.19 & 84.08 \\
\hline Ho & 75.50 & 47.66 & 79.83 \\
\hline Tamale & 85.04 & 53.68 & 89.92 \\
\hline Bolga & 132.96 & 83.92 & 140.59 \\
\hline $\mathrm{Wa}^{\circ}$ & 87.17 & 55.02 & 92.17 \\
\hline Weija & 83.33 & 52.60 & 88.11 \\
\hline Obuasi & 84.62 & 53.41 & 89.48 \\
\hline Techiman & 72.00 & 45.45 & 76.13 \\
\hline Denu & 64.47 & 40.70 & 68.17 \\
\hline Bekwai & 64.27 & 40.57 & 67.96 \\
\hline Mampong & 63.81 & 40.28 & 67.48 \\
\hline Nkawkaw & 64.40 & 40.65 & 68.09 \\
\hline Tarkwa & 66.39 & 41.91 & 70.20 \\
\hline Bivac-Kutunse & 93.61 & 59.08 & 98.98 \\
\hline Sked Somanya & 63.95 & 40.36 & 67.62 \\
\hline
\end{tabular}

Table 3: Registration fees for a year old three categories of vehicles at different registration offices

\begin{tabular}{llll}
\hline Registration office & \multicolumn{2}{l}{ Type of Vehicle } & \\
\hline & $\begin{array}{l}\text { Mercedes-Benz } \\
\text { C-Class } \\
\text { (Fees in GH } \boldsymbol{\phi} \text { ) }\end{array}$ & $\begin{array}{l}\text { New Audi A1 } \\
\text { Sportback 2019 } \\
\text { (Fees in GH } \boldsymbol{\phi})\end{array}$ & $\begin{array}{l}\text { Toyota Camry 2018 } \\
\text { (Fees in GH } \mathbf{c})\end{array}$ \\
\hline Accra & 102.68 & 64.81 & 108.58 \\
Tema & 192.97 & 121.80 & 204.05 \\
Kumasi & 77.31 & 48.80 & 81.75 \\
Takoradi & 75.55 & 47.69 & 79.89 \\
Sunyani & 103.49 & 65.32 & 109.43 \\
Koforidua & 100.56 & 63.47 & 106.33 \\
Cape Coast & 82.93 & 52.34 & 87.69 \\
Ho & 78.74 & 49.70 & 83.26
\end{tabular}


Table 3 (cont'd)

\begin{tabular}{llll}
\hline Registration office & \multicolumn{2}{l}{ Type of Vehicle } & \\
\hline & $\begin{array}{l}\text { Mercedes-Benz } \\
\text { C-Class } \\
\text { (Fees in GH } \boldsymbol{\phi})\end{array}$ & $\begin{array}{l}\text { New Audi A1 } \\
\text { Sportback 2019 } \\
\text { (Fees in GH } \boldsymbol{\phi})\end{array}$ & $\begin{array}{l}\text { Toyota Camry 2018 } \\
\text { (Fees in GH } \mathbf{~ ) ~}\end{array}$ \\
\hline Tamale & 88.68 & 55.98 & 93.77 \\
Bolga & 138.66 & 87.52 & 146.62 \\
Wa & 90.90 & 57.38 & 96.12 \\
Weija & 86.90 & 54.85 & 91.88 \\
Obuasi & 88.25 & 55.70 & 93.31 \\
Techiman & 75.09 & 47.39 & 79.40 \\
Denu & 67.24 & 42.44 & 71.10 \\
Bekwai & 67.03 & 42.31 & 70.88 \\
Mampong & 66.55 & 42.01 & 71.01 \\
Nkawkaw & 67.16 & 42.39 & 73.21 \\
Tarkwa & 69.24 & 43.70 & 703.22 \\
Bivac-Kutunse & 97.62 & 61.62 & 70.52 \\
Sked Somanya & 66.69 & 42.09 & \\
\hline
\end{tabular}

Table 4: Fees for three category of vehicles that break down on roads at different towns

\begin{tabular}{|c|c|c|c|}
\hline \multirow[t]{2}{*}{ Registration office } & \multicolumn{3}{|l|}{ Type of Vehicle } \\
\hline & $\begin{array}{l}\text { Mercedes-Benz } \\
\text { C-Class } \\
\text { (Fees in GHф) }\end{array}$ & $\begin{array}{l}\text { New Audi A1 } \\
\text { Sportback } 2019 \\
\text { (Fees in GH } \phi \text { ) }\end{array}$ & $\begin{array}{l}\text { Toyota Camry } 2018 \\
\text { (Fees in } \mathrm{GH} \dot{\text { ) }}\end{array}$ \\
\hline Accra & 436.31 & 349.16 & 449.87 \\
\hline Tema & 644.09 & 480.31 & 669.59 \\
\hline Kumasi & 377.92 & 312.30 & 388.13 \\
\hline Takoradi & 373.87 & 309.75 & 383.86 \\
\hline Sunyani & 438.17 & 350.33 & 451.84 \\
\hline Koforidua & 431.43 & 346.08 & 444.71 \\
\hline Cape Coast & 390.84 & 320.46 & 401.80 \\
\hline Ho & 381.20 & 314.37 & 391.60 \\
\hline Tamale & 404.09 & 328.83 & 415.81 \\
\hline Bolga & 519.10 & 401.42 & 537.42 \\
\hline $\mathrm{Wa}$ & 409.20 & 332.05 & 421.21 \\
\hline Weija & 399.98 & 326.23 & 411.46 \\
\hline Obuasi & 403.08 & 328.19 & 414.74 \\
\hline Techiman & 372.80 & 309.07 & 382.72 \\
\hline Denu & 354.73 & 297.67 & 363.62 \\
\hline Bekwai & 354.25 & 297.37 & 363.11 \\
\hline Mampong & 353.15 & 296.67 & 361.94 \\
\hline Nkawkaw & 354.56 & 297.56 & 363.43 \\
\hline Tarkwa & 359.34 & 300.58 & 368.49 \\
\hline Bivac-Kutunse & 424.65 & 341.80 & 437.55 \\
\hline Sked Somanya & 353.47 & 296.87 & 362.28 \\
\hline
\end{tabular}


Table 6: Registration offices and the numerical designation

\begin{tabular}{ll}
\hline Registration office & Number \\
\hline Accra & 1 \\
Tema & 2 \\
Kumasi & 3 \\
Takoradi & 4 \\
Sunyani & 5 \\
Koforidua & 6 \\
Cape Coast & 7 \\
Ho & 8 \\
Tamale & 9 \\
Bolga & 10 \\
Wa & 11 \\
Weija & 12 \\
Obuasi & 13 \\
Techiman & 14 \\
Denu & 15 \\
Bekwai & 16 \\
Mampong & 17 \\
Nkawkaw & 18 \\
Tarkwa & 19 \\
Bivac-Kutunse & 20 \\
Sked Somanya & 21 \\
\hline
\end{tabular}

